EDITORIAL

\title{
Turning Outwards, Turning Inwards
}

\author{
Helen Oosthuizen ${ }^{1 *}$, Susan Hadley ${ }^{2}$, Claire Ghetti $^{3}$ \\ 1 Anglia Ruskin University, England \\ 2 Slippery Rock University, USA \\ 3 GAMUT, The Grieg Academy, University of Bergen, Norway \\ *hb.oosthuizen@gmail.com
}

Published: 1 March 2022

The November issue of Voices urged music therapists, as well as musicians working for social and political change, to turn outwards. A turn outwards engendered attending to injustices in society, attending to continuing oppression. As we now turn outwards, we are aware of people fleeing their country or taking up arms as a war begins, people afraid and angry, we take note of the frustrations and exhaustion with the continuation of an already two years' long pandemic, and we notice injustices inherent within our context and within our clinical and professional work. As we turn inwards, we ask how can music therapy be relevant in places of war? Can it allow for expressions of the complex emotions associated with issues of such a broad scale? How can we each meaningfully respond to the challenges and conflicts of our era?

We are increasingly aware of the part each of us continues to play in an ongoing oppressive society and music therapy practice, at the same time as we take active steps to oppose injustices. As we turn outwards, we continue to recognise accumulated biases and assumptions resting (and perhaps also wrestling) within our public and private selves. It seems only apt that our many 'selves' are provoked, challenged, motivated and incited to change. In this spirit, the upcoming $12^{\text {th }}$ European Music Therapy Conference invites and welcomes participants to engage with the many ripples that emanate from a 'disturbance', with the theme: "Music Therapy in Progress: Please Disturb." This conference, as well as many of the papers published in this March issue of Voices highlight the importance of allowing disturbances to precede a turn inwards.

As music therapists have turned our perceptions outwards, we have developed many ways of working in diverse contexts. The articles in this issue bring perspectives on music therapy from Zambia, Japan, Argentina, Israel, New Zealand, Hungary, Britain, and the U.S. They include a variety of article types including perspectives on practice using storytelling or video-based reflective practice; a position paper; an essay; and diverse approaches to research utilizing autoethnography, Philosophy Café, focus groups and survey methods.

Using an autoethnographic approach, Carolyn Shaw describes her journey developing what she refers to as Post-Ableist Music Therapy (PAMT), which draws on posthumanism, agonistic pluralism, and disability studies. PAMT, according to Shaw, removes ableist barriers, supports moments of connection, finds new and less restrictive spaces to be in practices, creates an environment and experience that is less disabling, and one in which the therapist continually questions their frame of reference. 
Unlike social justice practices based on empowerment and humanism, PAMT relies on agonism and posthumanism. Shaw's article includes vignettes that are helpful in illustrating PAMT.

Challenging the outward stereotypes around aging, Aviya Riabzev, Ayelet Dassa and Ehud Bodner explore what engagement in group vocal improvisation can afford healthy older adults. Through a qualitative study using focus groups, the authors explore how older adults experienced free vocal improvisation as creating an open space for exploration of themselves and their voices. Participants' attitudes toward their voices changed during engagement in free vocal improvisation and they experienced meaningful self-discoveries. Participants were empowered by their experiences and expressed a new sense of capability and possibility that transferred to their lives outside of the group improvisation sessions. The authors underline the importance of vocal improvisation for healthy older adults, as a means for expanding identity, making meaning and self-expression.

Critically examining our practices in music therapy includes turning inward to address matters of representation and bring attention to unexamined assumptions and beliefs. Lorna Segall and Olivia Yinger focus on the practice of music therapy in correctional settings within the U.S. Their online survey explored the philosophy, practices and protocols of music therapists working in such settings, including reasons for choosing or declining such work. Segall and Yinger examine the correctional system in the U.S. and acknowledge the role that poverty and systemic racism play. The authors found a greater representation of music therapists identifying as non-white and as male in respondents who work in prison settings, versus those who do not. Segall and Yinger recommend that music therapists working in this setting should seek to understand the factors that impact policies in the correctional system and develop reflexivity around how their intersectionality influences their practice in the corrections context.

In a pair of articles drawn from a survey study, Tony Meadows, Lillian Eyre, and Audra Gollenberg examine work satisfaction levels, workforce characteristics, workplace and job satisfaction, stress, burnout, and happiness of music therapists in the U.S. Regarding work satisfaction levels, their mixed methods study found that work satisfaction levels were significantly associated with stress, burnout, and happiness, and were connected to their identities as music therapists. The results of this research provide important insights into the occupational wellbeing of the profession of music therapy in the U.S. Their research also provided a comprehensive portrayal of the U.S. music therapy workforce. They found that in general music therapists are happy with their workplace and job conditions and experience moderate stress and low burnout. The most concerning finding in their research concerned the income for music therapists, which are very varied and often quite low for early-career music therapists. This suggests the need for more advocacy efforts in this area. The two studies together provide a comprehensive view of the occupational wellbeing of the music therapy profession in the U.S.

Sekyung Jang recognizes the importance of fostering reflective practice in music therapy training and presents a practical methodology for video-based reflective practice. Jang's methodology consists of self-observation of video-recorded sessions with questions to structure reflection. The process helps music therapy trainees identify the "reciprocal and cyclical" aspects of their practices as a means of gaining insight on dynamics and developing clinical reasoning skills. Jang envisions this structured reflection as being relevant for professional development, peer supervision and clinical supervision.

Utilizing the Philosophy Café method, 三宅 博子(Hiroko Miyake), explores her work with a disabled adolescent client who she has been working with for seven years. A driving question in this work has been around how she can make music with this client. She asks this not superficially, but in reference to the larger social structure and various values and relationships within that structure. To explore this question deeply, the Philosophy Café method allowed her to dialogue for about two hours with a group of people unrelated to her work with this client, including music therapists, musicians, 
and other people interested in dialoguing about it. The idea is to learn from a variety of viewpoints and to enable new perspectives to emerge. Including people outside of music therapy enables thorough examination of words and concepts we use in music therapy that have largely been developed from a Western-centric perspective and to challenge these. This article has been published in Japanese and in English.

Nsamu Moonga illustrates the use of storytelling as a celebration of heritage and culture. Given the mythopoetic potency that stories have had on his own life, he honours the power they can hold for many people in music therapy. Stories possess rich and complex traditions that have been passed down through the generations, often through oral traditions. He suggests that stories are representations of art and community and that storytelling is a way of building community. Storytelling in a community draws on the aesthetics of that community. As we come together in music therapy as a community of communities, Nsamu's contribution reminds us how important it is to embrace a wide array of storytelling traditions within Voices.

Considering how participating in a choir enables social connection, Zsófia Fekete and Fanni Eckhardt explore how members of the Hungarian Aphasia Choir experienced online versus offline rehearsals during the time of the COVID-19 pandemic. Turning our attention inwards at the choir members' experiences and contextualizing them outwards in relation to the international community of aphasia choirs, the authors sensitize us to the increased burden the pandemic has caused for people who communicate in alternative ways. Online participation increased accessibility for some choir members, while for others, such solutions could not match the psychosocial benefits and feelings of community that in-person rehearsals bring.

Music therapist Helen Bonny responded to her own experiences of working with clients in the area of mental health. She noted that: "I felt that hearing carefully chosen samples of this music while in a very relaxed state of consciousness could facilitate in evoking important memories and in working through conflicts in the context of psychotherapy ... the harmonic integration of inspired music could also bring about healing and transformation when the client was ready to receive it" (Bonny, 2001, para. 3). Her development of the model was strongly influenced by her own experiences, as she turned outwards towards the context where she worked. As Guided Imagery and Music (GIM) has expanded and developed as a field internationally, Martin Lawes turns inwards to reconsider the practice. How do we define GIM? Who is qualified to practice? What boundaries need to be in place to ensure that this practice is transformative rather than mundane, or even harmful for clients?

Nuria Inés Alicia Marsimian provides a thoughtful review of the book, Fundamentos de Avaliação em Musicoterapia [Essentials of Music Therapy Assessment](2020) by Gustavo S. Gattino. Gattino's book is published in Portuguese, a language that Marsimian accesses through her own Spanish language. The book is also published in English. Marsimian weaves together a review of the book with a recounting of the development of her own thinking in relation to music therapy assessment of children. Marsimian brings concepts from the book to life by contributing a practical visualization of the continuous assessment process for the children with whom she engages in music therapy. Through the course of the review, Marsimian educates the reader in the unique ways Gattino opens up our thinking about assessment, while she also provides personal and practical examples of how such thinking has evolved in her own work. The book review is published in Spanish and in English.

At this intersection of reflecting inwards and turning outwards, we take the opportunity to thank Bec Blakeney for her attentive service as copyeditor. Bec joined the Voices team in a time of change and skilfully helped expand our team of copyeditors. We wish her well as she takes on new responsibilities at this time. We also take this opportunity to thank Mike Viega for his creative suggestion to initiate and serve in the position of Communications Editor for Voices. His dedication to the mission of the journal through long terms on the editorial team and as a peer reviewer has been invaluable and he will be missed. As Mike turns attention toward other important com- 
mitments, we recognize the innovation and energy he has brought to assuring Voices authors and readers are heard and appreciated on a broader scale.

In this March issue, many authors have questioned, wrestled with and found ways to allow outer experiences to realign what music therapy is and could be, whilst simultaneously ensuring that our profession remains one that continues to transform lives and systems.

A cycle continues. Music therapy influences people (turning inwards), and people influence music therapy (turning outwards). We do hope that this March issue will continue this disturbing and yet refreshing cycle.

\section{References}

Bonny, H. (2001). Music psychotherapy: Guided Imagery and Music. Voices: A World Forum for Music Therapy, 10(3). https://doi.org/10.15845/voices.v10i3.568 